\title{
TALENT IDENTIFICATION PRACTICES AND CHALLENGES OF COACHES: IN IDENTIFYING TALENTED YOUNG FOOTBALL PLAYERS
}

\author{
Alemmebrat Kiflu \\ Addis Ababa University, CNCS, Department of Sport Science, Ethiopia
}

Original scientific paper

\begin{abstract}
"You reap what you sow". The foundation of future success of elite football players that represent the country football lies at grass root level through proper talent identification and development process. This should be strongly synchronized. The aim of this paper was to examine the current talent identification practices of Ethiopian youth sports academy football coaches and their main challenges while implementing the identification process. To investigate the problem, mixed research design was employed. In-depth interview as well as a five point Likert item questions were used as a means to obtain valid and reliable data among 76 study participants aged ranged between 25 to $65( \pm 5)$ using purposive and snowball sampling method. The interview was analysed qualitatively while SPSS version 17 software was applied as a statistical tool for the analysis of quantitative data. Results obtained from the triangulated data indicated that coaches identify talented young football players based on their overall performance at an arranged trail game /competition/ situation. Great attention was given to technical and tactical skills. Few efforts have been carried out to implement on the potential predictors of talent, like anthropometric, physiological, psychological and sociological predictors but it had not purely a scientific basis. This study also revealed that coaches' problems were various, but broadly categorized in four pillars as technical, economical, administrative and sociocultural. It is there for concluded that based on its responsibility and mission, the sport academy should give due attention to the magnitude of problems in discussing the problem of the coaches with higher institution professionals and other stakeholders, besides to this, talent identification process and tasks should never be left to the coaches alone, rather talent scouts should be invited and participated actively for a better result.
\end{abstract}

Key Words: Talent Scout, Talent, Talent Identification, Youth, Sport Academy

\section{INTRODUCTION}

It has been established that the aim of talent detection and identification is to provide an accurate prediction of those individuals who have the potential to compete successfully at worldclass levels. Such talent detection and identification procedures tend to be employed with pre-pubescent or pubescent children so that selected children can complete the number of years practice which has been demonstrated as required to achieve excellence (Ericsson et al., 1993). However; to the researcher knowledge, experience and observation, there might be a great gap among coaches and other segments of our society to understand the real meaning of talent and talent detection or identification.

The American Heritage Electronic Dictionary (1992) defined talent as "a marked innate ability," where innate means "possessed at birth; inborn" and inborn means "possessed by an organism at birth.....inherited or hereditary." Williams \& Reilly, (2000) defined talent identification as "the current recognition process of participants with the potential for becoming elite players". It is generally considered a natural, exceptional ability which, through development, leads to remarkable results. Vaeyens et.al (2008) also described talent identification as the process of recognising current players that have the potential to excel within football while Abbott \& Collins, (2002) stated that talent selection is the acceptance of individuals into representative teams and development programmes. Balyi and Hamilton, (1995) explained that talent identification generally takes the form of the selection of a series of tests that are thought to measure key factors for success in a specified sport, as a result it predict the future capacity of performance of an individual.

In Ethiopia, empirical studies which shows experiences of football coaches in identifying talented young football players are scanty besides to this the kind and magnitude of coaches problem is not properly addressed in those previous studies. Only few studies were conducted in the area of track and field by graduate students as partial fulfilments for the degree of masters of Science in sport science, however; these studies lack proper methodological approach and in-depth findings. Having understood all this gaps, the current study identified the problem and investigated talent identification experiences of Ethiopia youth sport academy (EYSA) football coaches and their major difficulties. 


\section{RESEARCH DESIGN AND METHODS Research Design}

Mixed method is now becoming increasingly popular. A mixed methods research design is a procedure for collecting, analyzing, and "mixing" both quantitative and qualitative research and methods in a single study to understand a research problem (Creswell, J. 2012). Up on the study problem, this study is therefore, employed descriptive mixed research design method.

\section{Study Participants}

In this study a total of 76 participants were participated. Among these respondents 14 of them participated in the qualitative part (indepth interview) and the remaining 62 informants were participated in the quantitative part (Likert scale items). Patton, 1996, stated that in qualitative research, the sample is small and not chosen randomly rather the choice of a sample is purposeful, thus, the researcher believe that fourteen (14) informants were adequate enough to capture qualitative data to this study based on the population size.

To capture quantitative data both purposive and snowball sampling method were employed. The former sampling method (purposive) was applied to select sport academy football coaches' $(\neq 9)$ and non-football coaches (potential respondents') within the sport academy $(\neq 15)$. In many cases purposive sampling is used in order to access 'professional people', i.e. those who have indepth knowledge about particular issues, maybe by virtue of their professional role, power, access to networks, expertise or experience (Ball 1990). The latter sampling method (snowball) was employed to select potential respondents' outside-the sport academy $(\neq 38)$.

\section{Instrumentation}

In this study two data collection instruments were employed, namely questionnaire and semistructure interview. The questionnaire consisted of 11 questions item to be rated on a five point Likert scale (1 strongly disagree to 5 strongly agree). These questions were divided into five categories such as: technical skills; tactical skills; potential predictors of talent in football; recording habit for mature consideration and equipment, facility with laboratory settings of the sport academy. The interview parts comprise two major questions. The first one is, talent identification experience of the sport academy football coaches, while the second one is major difficulties that challenges coaches while employing talent identification tasks.

\section{Procedures}

Prior to the study, the researcher obtained verbal consent from the participants' as a result the study could be conducted without any difficulties. This study was carried out by distributing the questionnaire to the participants through their email and postal address and also in person. Semi-structured face-to-face in-depth interview were also conducted in one sitting in a quiet environment with selected potential interviewees and were facilitated by the researcher himself. The face-to-face interview enables the interviewer to observe visual clues and also allows the observation of body language which might indicate comfort or discomfort, thus giving the interviewer clues on how to proceed. For some interviewees, telephone interview ranged in length from 10 to 15 minutes were used.

\section{Reliability and Validity of Instruments}

For the purpose of reliability and validity of the instrument the following procedure was done. Prior to administer the questionnaire to the respondents, the reliability of each question items were checked through Cronbach's Alpha, and average value of $(0.79)$ was obtained as depicted in table-1 below.

To establish the validity of the instruments, items were critically reviewed by professional and language experts to judge the extent to which the items in the instrument sufficiently measured the intended research problem. Besides to this, pilot study was conducted in small groups who have similar characteristics of the main participants and the instrument was refined based upon the feedbacks obtained on the pilot participants. After passed through this step respondents completed the questions on the scale as: strongly agree $=5$; agree $=4$; neutral $=3$; disagree $=2$ and strongly disagree 
TABLE 1. The Alpha $(\alpha)$ Coefficient of Reliability for Each Item Questions ( $N=28)$

\begin{tabular}{llcc}
\hline No & \multicolumn{1}{c}{ Variables: Coaches Considerations to } & \# Questions & Alpha $(\alpha)$-value \\
\hline 1 & Technical skills & 4 & 0.83 \\
2 & Tactical skills & 2 & 0.76 \\
& $\quad$ Potential predictors of talent in Football & & \\
3 & Physical Factors/predictors & 3 & 0.84 \\
4 & Physiological Factors/predictors & 3 & 0.63 \\
5 & Psychological Factors/predictors & 4 & 0.76 \\
6 & Sociological Factors/predictors & 3 & 0.77 \\
7 & Recording habit for Mature Consideration & 4 & 0.86 \\
8 & Equipment, Facility \& Laboratory settings & 5 & 0.82 \\
& $\quad$ Total & 28 & 0.79 \\
\hline
\end{tabular}

\section{Ethical Considerations}

In this study, confidentiality and informed consent received great weight. Therefore, respondents were fully informed about the aims of the study and a verbal consent was obtained before conducting the study. The respondents were also told about the confidentiality of their responses; i.e. any information participants provide will not be publicly reported in a manner that identifies them and will not be made accessible to others. In short their data and identities were protected not to be disclosed to anybody in any manner and kept in a secured way. In this way the respondents' right to confidentiality were respected.

\section{Data Analysis}

Marshall and Rossman (1999) describe data analysis as the process of bringing order, structure and meaning to the mass of collected data. It is described as messy, ambiguous and timeconsuming, but also as a creative and fascinating process. Having considered this fact, the quantitative and qualitative data were analysed independently.

To analyse the quantitative data, obtained from the five point Likert scale items questions, descriptive statistics was employed using SPSS (Statistical Package for Social Science) version 17 for Windows. The results were tested with nonparametric tests of significance. The level of significance was set at $P<0.05$.

In addition to this, the qualitative data was analysed qualitatively, which means that, the interviewer, interviews the interviewees. The narrative data or verbal content obtained from the interviewees (verbatim transcription of interviews) took place by means of note-taking. To ensure reliability and validity of data, the transcribed interviews were presented to respondents to verify and confirm the contents of the interviews. The respondents signed and returned the transcribed text. Then after, the transcribed texts (data) were systematically organized, arranged and grouping similar kinds of information together in meaningful themes and categories. Using the coding technique the written transcripts were coded the content (topics) of talk thematically. Themes were analysed with the help of qualitative data analysis computer software (SPSS version 20) and interpreted for frequency, repetition, and dominance of discursive interpretations.

\section{RESULTS}

The results of this study are presented in table forms. It comprises two types of data i.e. quantitative and qualitative and each data were computed separately for the purpose of simplicity. However, to increase the validity of the data, respondents response were triangulated, in this case response of sport academy football coaches' $(N \neq 9)$; selected potential respondents within sport academy $(n \neq 15)$; selected potential respondents' outside the sport academy $(\neq 38)$ actively participated in the quantitative part however, 14 interviewees took part in the qualitative part. Therefore, a total of 76 informants' results were computed and displayed as follows. 


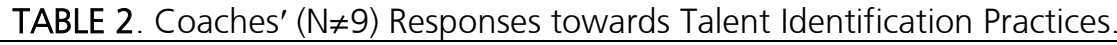

\begin{tabular}{lccccccr}
\hline Items & SD & DIS & UN & AGR & SAGR & Mean & Std. Deviation \\
\hline$\neq 1$ & - & - & - & $2(22.2 \%)$ & $7(77.8 \%)$ & 4.7778 & .44096 \\
$\neq 2$ & - & - & - & $9(100 \%)$ & - & 4.0000 & .00000 \\
$\neq 3$ & $4(44.4 \%)$ & $5(55.6 \%)$ & - & - & - & 1.5556 & .52705 \\
$\neq 4$ & $4(44.4 \%)$ & $5(55.6 \%)$ & - & - & - & 1.5556 & .52705 \\
$\neq 5$ & - & - & - & $9(100 \%)$ & - & 4.0000 & .00000 \\
$\neq 6$ & - & - & - & $9(100 \%)$ & - & 4.0000 & .00000 \\
$\neq 7$ & $3(33.3 \%)$ & $5(55.6 \%)$ & - & $1(11.1 \%)$ & - & 1.8889 & .92796 \\
$\neq 8$ & - & $5(55.6 \%)$ & - & $4(44.4 \%)$ & - & 2.8889 & 1.05409 \\
$\neq 9$ & - & $6(66.7 \%)$ & - & $3(33.3 \%)$ & - & 2.6667 & 1.00000 \\
$\neq 10$ & - & - & $3(33.3 \%)$ & $1(11.1 \%)$ & $5(55.6 \%)$ & 4.2222 & .97183 \\
$\neq 11$ & & & & & & 2.1111 & 1.16667 \\
\hline
\end{tabular}

Key. SD-strongly disagree; DIS-disagree; UN- undecided; AGR- agree; SAGR- strongly agree. Item $\neq 1$ technical skill consideration; Item $\neq 2$ tactical skills consideration; Item $\neq 3$ only specifics skills; Item $\neq 4$ only basic skills; Item $\neq 5=$ both specific and basic skill consideration; Item $\neq 6$ anthropometrical predictors of talent consideration; Item $\neq 7$ physiological predictors of talent consideration; Item $\neq 8$ psychological predictors of talent consideration; Item $\neq 9$ sociological predictors of talent consideration; Item $\neq 10$ maturation recording habits of talented players; Item $\neq 11$ equipment, facilities \& laboratory status of the academy.

TABLE 3. Sport academy potential respondents' $(N \neq 15)$ response towards football Coaches Practice in identification of talent described as descriptive statistics.

\begin{tabular}{cccccccr}
\hline Items & SD & DIS & UN & AGR & SAGR & Mean & Std. Deviation \\
\hline$\neq 1$ & - & - & - & $7(46.7 \%)$ & $8(53.3 \%)$ & 4.5333 & .51640 \\
$\neq 2$ & - & - & - & $15(100 \%)$ & - & 4.0000 & .00000 \\
$\neq 3$ & - & $15(100 \%)$ & - & - & - & 2.0000 & .00000 \\
$\neq 4$ & - & $15(100 \%)$ & - & - & - & 2.0000 & .00000 \\
$\neq 5$ & - & - & - & $15(100 \%)$ & - & 4.0000 & .00000 \\
$\neq 6$ & - & - & - & $15(100 \%)$ & - & 4.0000 & .00000 \\
$\neq 7$ & - & $13(86.7 \%)$ & - & $2(13.3 \%)$ & - & 2.2667 & .70373 \\
$\neq 8$ & $6(40 \%)$ & $8(53.3 \%)$ & $1(6.7 \%)$ & - & - & 1.6667 & .61721 \\
$\neq 9$ & - & $12(80 \%)$ & $1(6.7 \%)$ & $2(13.3 \%)$ & - & 2.3333 & .72375 \\
$\neq 10$ & - & $6(40 \%)$ & - & $7(46.7 \%)$ & $2(13.3 \%)$ & 3.3333 & 1.17514 \\
$\neq 11$ & - & $12(80 \%)$ & - & $3(20 \%)$ & - & 2.4000 & .82808 \\
\hline Key
\end{tabular}

TABLE 4. Other Professional and sport persons $(\mathrm{N} \neq 38)$ reflection towards Sport Academy Football

Coaches Talent Identification practice described as Descriptive Statistics.

\begin{tabular}{|c|c|c|c|c|c|c|c|}
\hline Items & SD & DIS & UN & $A G R$ & SAGR & Mean & Std. Deviation \\
\hline$\neq 1$ & - & - & $4(10.5)$ & $14(36.8)$ & $20(52.6)$ & 4.4211 & .68306 \\
\hline$\neq 2$ & - & $6(15.8)$ & $7(18.4)$ & $22(57.9)$ & $3(7.9)$ & 3.5789 & .85840 \\
\hline$\neq 3$ & $5(13.5)$ & 26.(68.4) & $4(10.5)$ & $3(7.9)$ & - & 2.1316 & .74148 \\
\hline$\neq 4$ & $3(7.9)$ & $27(71.1)$ & $4(10.5)$ & $2(5.3)$ & $2(5.3)$ & 2.2895 & .89768 \\
\hline$\neq 5$ & - & $3(7.9)$ & $2(5.3)$ & $24(63.2)$ & $9(23.7)$ & 4.0263 & .78798 \\
\hline$\neq 6$ & - & - & $6(15.8)$ & $29(76.3)$ & $3(7.9)$ & 3.9211 & .48666 \\
\hline$\neq 7$ & $2(5.3)$ & $18(47.4)$ & $9(23.7)$ & $6(15.8)-$ & $3(7.9)$ & 2.7368 & 1.05739 \\
\hline$\neq 8$ & $8(21.1)$ & $22(57.9)$ & $1(2.6)$ & $5(13.2)$ & $2(5.3)$ & 2.2368 & 1.10121 \\
\hline$\neq 9$ & $4(10.5)$ & $20(52.6)$ & $9(23.7)$ & $5(13.5)$ & - & 2.3947 & .85549 \\
\hline$\neq 10$ & - & $7(18.4)$ & $6(15.8)$ & $17(44.7)$ & $8(21.1)$ & 3.6842 & 1.01623 \\
\hline$\neq 11$ & - & $21(55.3)$ & $8(21.1)$ & $9(23.7)$ & & 2.6842 & .84166 \\
\hline
\end{tabular}

Key. The abbreviation of Likert scale and description of items in table-4 is as equal as table-2\&3. 


\section{DISCUSSION}

In this section, the result obtained from qualitative and quantitative section were clearly explained and interpreted. The results of the study were also compared with those of other studies and relevant findings. Analyses of the study were also done. The study finding or results were relating to theory and accepted principles dealing with the topic. Limitations of the study were addressed and finally implication that is possible applications of the results were forwarded.

As indicated in table-2, the experience of the football coaches in identifying talented young football players were done in considering technical and tactical skills or attributes based upon game situations. The data were triangulated from the response of the coaches indicated in table-2; the response of the sport academy potential respondents' as indicated in table-3 and also the response of the other professional and sport persons as indicated in table-4. Therefore, the results were conformed. Prior studies and relevant findings reported in a similar fashion as the findings of the present study. For example Williams and Reilly (2000) strongly believe that young players should be selected considering technical skills rather than physical dimensions. In agreement with Williams and Reilly (2000), Gidu, Diana, et al. (2010) study also stated that Technical ability involves not only the correct execution of a technical element (passing, stopping, receiving, kicking), but also the adaptation of motric behaviour to the actual situation due to the nature of the field, wind, speed and direction of the ball. Therefore, it contains sensory elements (external perception, proprioception - kinetic sensations and balance), logical understanding of the situation (reported to the task and intent), and data memory, combined with specific skill'". Reilly and Holmes (1983) also stated that tests for passing, shooting, controlling and dribbling the ball are the principal components in assessment of skilled play.

As we observe from table 2, 3 and 4 the sport academy coaches also consider tactical skills. In relation to these skills, Sćther (2004) reported that tactical skills are the most important skill in identifying talented players. The sport academy coaches give great attention to both general and specific football skills in identifying talented football players. This finding was supported by previous studies. For example, Christensen (2009) reported that most Danish national youth coaches focused mostly on specific skills while a large group of Norwegian elite coaches focused on basic skills (Sćther 2014). However, the elite coaches seem to be focused on both basic and extreme skills, while some see these skills in relation.

Talent identifications Models and accepted principles and Theory

Many countries in the world, including Ethiopia sport academy coaches follow different talent identification models; from simple subjective identification process to scientifically systematic objective approach based on various factors such as from the countries own many years' successful stories, expertise to implement the program and availability of resource. Therefore, studies indicated that different countries used different talent identification models such as: (1) natural selection or performance models or traditional approach (2) anthropometrical and physiological models (3) generic model (4) sport interactive model and (5) multidimensional model/approach.

For example, the use of scientific talent detection and identification programmes was initiated within East and Central European countries (Bompa, 1994). These models were based almost exclusively on identifying the physical and anthropometrical characteristics of elites in younger athletes. Indeed, the Olympic success of Bulgaria, Romania, and East Germany in the 1960s and 1970s has been attributed largely to scientific talent detection processes (Bompa, 1994). As a result of successful sporting countries employing anthropometric based TI models, similar systems have emerged, and continue to emerge, worldwide. For example, within China, the selection of gymnasts occurs by considering the physical and anthropometrical profile of children aged 7 to 9 years Ho, (1987, cited in Abbott A. et.al 2002). Within Canada, although ultimate selection is determined by performance within competition, initial selection of gymnasts is also based on physique: The Canadian testing program has concentrated very heavily on physical characteristics [e.g., weight and height] when considering young athletes, since their chances to succeed are slim when they don't have those qualities Bajin, (1987, cited in Abbott A. et.al 2002).

The Ethiopia sport academy football coaches' talent identification experience findings showed that subjective anthropometric and physiological measurements were assessed. However; a scientific laboratory based physiological measurement such as aerobic (maximum oxygen uptake $\mathrm{Vo}_{2} \mathrm{max}$ ) and anaerobic capacity measurement were not conducted. Similarly, other potential predictors such as psychological and sociological variables were not assessed in a scientific approach rather the latter variables were viewing in a trial game or competition manner. Bompa (1999) believes that psychological 
capacity is the most important factor in talent detection and identification process.

Generally, from the above listed talent identification models perspective, the Ethiopia sport academy coaches' favoured natural selection, traditional approach, or competitive performance models. In relation to this finding, previous studies described that natural selection means based on competitive performance (best rising to the top) and selective ID by coaches (nose and eyes). Traditional TI procedures have been categorized by many authors as 'natural selection' (e.g. Bompa, 1994, 1999), and in this setting, identification usually was aimed at individuals already in a sport. Of course, this sport involvement may have resulted purely from peer or parental pressure, proximity of facilities, or of the sport's popularity in that geographical area, and it would be coincidental for an individual who chooses a sport in this way to excel. For the majority therefore, who had not 'happened upon' their perfect match, performance evolution in the activity would be slow, as training would have to enable them to overcome innate deficiencies. Unfortunately, whilst East Europe has been moving away from this traditional approach such methods have persisted in the West until this day. Current initiatives, however, are aiming to adopt a more scientific selection process.

One of the disadvantages of using only this type of model is that, the chances of talented football players are purely depend on the coaches' knowledge, experience and interest. Williams \& Reilly, 2000 stated that talent identification has traditionally been based on viewing athletes in a trial game or training session environment, whereby the players aim to impress coaches. This approach to talent selection or recruitment is not informed by scientific evidence, but rather coaches' subjective preconceived notion of the ideal player, which used in isolation, may result in repetitive misjudgements and limited consistency. Even though, the above mentioned talent identification models have their own limitation; many literatures and empirical studies recommend the multidimensional model or approach. The advantage of this model is well described by Reilly et al. (2000) as follows. A multi-dimensional approach of talent identification should include a battery of sport specific skills (e.g., dribbling, shooting, ball control, passing, etc.) in combination with physical, physiological, psychological tests and sociological consideration. Sport-specific skills have been used as predictors of success in soccer.

In recognition of the need for a multidisciplinary approach to talent identification, Reilly et al.
(2000) proposed a multi-factorial interdisciplinary TI scheme for football. The test battery was piloted on 31 boys, about 16 years old. The testing protocol comprised 15 anthropometric measurements, 8 physiological measurements, 3 psychological tests and 2 skill tests. Statistical analysis of the data from the battery of tests indicated that a combination of four variables successfully discriminated between elite and subelite players.

Different studies reported the advantage of multidisciplinary approaches. For example, Auweele et al., 1993 stated that physical/anthropometrical, physiological, psychological and sociological profiles of adolescents are the best indicators of potential talent within different sports. This more structured and holistic approach would account for a greater proportion of the variance between talented and less talented players, promoting greater accuracy and improved understanding of the talent identification process. Furthermore, Sćther (2014) reported that many of the elite coaches pointed to the importance of a holistic perspective, by focusing on the individual overall. Simonton's (1999) also reported that although superior performance in games, sports, science, and the arts is often ascribed to talent, the hypothesized phenomenon may not be fully understood unless it is conceived as a multidimensional and multiplicative development process. Hoare and Warr, (2000) also reported that as successful soccer performance is a complex interplay of multiple interacting skills and qualities, it is recommended youth soccer coaches should consider a holistic multidisciplinary approach to talent identification, rather than isolated assessments of individual skills and qualities.

On the other side, other studies reported that great emphases should be given to growth and maturity. This is because there are individual difference among adolescences in growth and maturity. For example, some individuals are matured early and the others are late matured, so care should be considered in selecting talented athletes with predictors variables. Welsman \& Armstrong, (2000), stated that anthropometric, physical and physiological variables have been correlated positively with performance, as the earlier review of literature clearly shows; the determinants of performance and potential at adolescence are likely to differ. Due to their unstable nature, mature values are hard to predict. For instance, an individual who is relatively small during adolescence will not necessarily retain this characteristic into adulthood. In similar fashion, since aerobic capacity is affected by body mass and maturity, 
performance on the multistage fitness test is also unlikely to remain relatively stable between individuals. Similar problems exist with measuring anaerobic capacity since the metabolic characteristics underpinning the relevant energy responses are also subject to growth influences. As indicated in the above quantitative and qualitative data, the Ethiopia sport academy football coaches consider the anthropometrical characteristics of young talented football players as one selection parameter during the talent identification period, however; due attention and consideration should be given to the growth and maturity of the players in the identification of talented young football players.

\section{DISCUSSION OF THE INTERVIEW PART}

In this part football coaches' talent identification experience and challenges narrative data were presented and discussed as follows.

Question One:

- Could you please tell me about coaches or (you as a coach) experience in selecting young talented football players to the sport academy?

Result obtained from the above Qualitative Data: Almost all interviewees, reported that young talented football players are recruited at the arranged competition by their overall game performances in a subjectively manner.

Question Two:

- What does a subjectively manner mean, could you please elaborate?

Result obtained from the above Qualitative Data: Nearly all interviewees stated that tournaments were arranged in different regions of the country and in those competitions; coaches were deployed across the country to identify talented players. During this time, coaches received selection criteria format or checklist which is prepared and approved by the sport academy training and education department. Based on the format or standard coaches identify talented young football players in considering the following variables, such as: general and specific technical and tactical skills; overall performance like physical and mental toughness; physiological parameters like aerobic and anaerobic capacity; anthropometry characteristics like height; health and skill related physical fitness; playing positions i.e. skill to play in a position; age and general health status of the players. Finally, each assessor points were computed and based on the mean result rank was given then the players who scored better results in their playing position were selected.

\section{Question Three:}

- Could you please tell me about the key problems that challenge you or football coaches to select talented young football players during the talent identification periods?

Result obtained from the above Qualitative Data: The result of part-two interview indicated that the magnitude of football coaches' problem is not single one rather it was found multi-dimensional, networked and interconnected. However; it is broadly categorized as technical, economical, administrative and sociocultural.

\section{Question Four:}

- Tell me in detail about what technical, economical, administrative and sociocultural problems mean?

\section{Result obtained from the above Qualitative Data:} The higher percentage of the interviewees described the problems as follows: Lack of efficient systems, infrastructures and strategies; Talent identification or recruitment processes of young talented football players were exclusively done on the base of trainees' performance showing at the Ethiopia football project championship computations rather than focusing on talent; Constrain of budget, inadequate time per game, insufficient number of game frequency, and resources in relation to the players' number to make an in-depth assessment; Unable to address objective measurement through scientific laboratory testing approach as results coaches rely only on field based tests to assess potential predictors of talent and other key variables in football, Thus, field observation through subjective evaluation was the main approach and this situation exposed coaches to depend only on their knowledge, experiences and interest; Lack of inadequate and trained skilled man power/expertise group/ for talent identification process; Lack of suitable football field and working environment to identify exhaustively talented young football players repeatedly throughout the country; Lack of smooth, clear and efficient bilateral agreement $\mathrm{b} / \mathrm{n}$ regional coaches or office with sport academy; Lack of teamwork and cooperation with local sport authorities and other professionals ; Lack of professional supervisors; Absence of properly registered and genuine age of the talented young football players; Parents' willingness to release players to the sport academy; Coaches did not use updated, latest or modern talent identification format or documents; Have a wrong belief in that some group of people have a belief that talent is confined or limited only in certain places rather than searching in everywhere. 


\section{CONFLICT OF INTEREST STATEMENT:}

The authors declare that the research was conducted in the absence of any commercial or financial relationships that could be construed as a potential conflict of interest.

\section{ACKNOWLEDGMENTS}

Special thanks should be given to Ethiopian youth sports academy football coaches to their valuable and constructive participation to this study. Their willingness to give their time so generously has been very much appreciated. I would also like to extend my thanks to all those potential respondents.

\section{REFERENCES}

1. Abbott, A., \& Collins, D. (2002). A theoretical and empirical analysis of a 'state of the art 'talent identification model. High Ability Studies, 13(2).

2. Abbott, A., Collins, D., Martindale, R., \& Sowerby, K. (2002). Talent Identification and Development: An Academic Review. Edinburgh: sportscotland: The University of Edinburgh.

3. American Heritage Electronic Dictionary ( $3^{\text {rd }}$ ed.). (1992). Boston: Houghton Mifflin.

4. Auweele, Y.V., Cuyper, B.D., Mele, V.V. and Rzewnicki, R. (1993). Elite performance and personality: From description and prediction to diagnosis and intervention. In A Handbook of Research on Sports Psychology (edited by R. Singer, M. Murphey and L.K. Tennant), pp. 257 2 292. New York: Macmillan.

5. Ball, S. J. (1990) Politics and Policy-Making in Education. London: Routledge.

6. Balyi, I. and Hamilton, A. (1995) "The concept of long term athlete development." Strength and Conditioning Coach Vol. 3, No. 2 .

7. Bompa, T. O., \& Haff, G. G. (2009). Periodization: theory and methodology of training. United States of America: Champaign, Human Kinetics.

8. Bompa, T.O (1994). Theory and methodology of training: the key to athletic training. Champaign: Human Kinetics.

9. Bompa, T.O (1999). Periodization: theory and methodology of training. Champaign: Human Kinetics.

10. Christensen, M.K. (2009) "An eye for talent": Talent identification and the "practical sense" of top-level soccer coaches. Sociology of Sport Journal, 26, 365-382. . (Found in Instrument Literature)

11. Creswell, J. (2012). Educational research: Planning, conducting, and evaluating quantitative and qualitative research ( $4^{\text {th }}$ ed.). Upper Saddle River, NJ: Pearson Education.

12. Ericsson, K.A. Krampe, R.T., Tesch-Romer, C. (1993). The role of deliberate practice in the acquisition of expert performance. Psychological Review. 100. 3, 363-406.

13. Gidu, D. V., Straton, A., Gidu, J. E. (2010). "Psychological Characteristics on woman soccer players." Ovidius University Annals, Series Physical Education and Sport/Science, Movement and Health, vol. 10, no.2. 497-498. Retrieved from http://analefefs.ro/anale-fefs/2010/issue-2-supplement/full part1.p. (Found in Instrument Literature).

14. Hoare DG and Warr CR. (2000).Talent identification and women's soccer: An Australian experience. J Sports Sci.; 18(9): $751 \pm 758$. https://doi.org/10.1080/02640410050120122 PMID: 11043900

15. Marshall, C., \& Rossman, G.B. (1999).Designing qualitative research ( $3^{\text {rd }}$ Ed.). Sage Publications, Inc.

16. Patton, M. Q. (1996). Qualitative Evaluation and Research Methods (2nd ed.). Newbury Park, CA: Sage Publications, Inc.

17. Reilly, T. and Holmes, M. (1983). A preliminary analysis of selected soccer skills. Physical Education Review, $6,64 \pm 71$. (Found in Instrument Literature).

18. Reilly, T., Williams, A.M., Nevill, A. and Franks, A. (2000). A multidisciplinary approach to talent identification in soccer. Journal of Sports Sciences, 18:9, 695-702.

19. Simonton, J.L. (1999) Talent and its development: an emergenic and epigenetic model. Psychological Review, $106,435-457$.

20. Stig Arve Sćther (2014). Identification of Talent in Soccer - What Do Coaches Look For? www.idrottsforum.org/saether140319.

21. Vaeyens, R., Lenoir, M., Williams, A. M., \& Philippaerts, R. M. (2008). Talent identification and development programmes in sport: current models and future directions. Sports Med, 38(9), 703-714.

22. Welsman, J.R., \& Armstrong, N. (2000). Longitudinal changes in submaximal oxygen uptake in 11-to 13-year olds. Journal of Sport Sciences. 18, 3, 183-189

23. Williams, A.M., \& Reilly, T. (2000). Talent identification and development in soccer. Journal of Sports Sciences, $18: 9,657-667$.

24. Woods, C. T. (2015). The development of an objective multi-dimensional approach to talent identification in junior Australian football. [Electronic reference]; Retrieved from https://ro.ecu.edu.au/theses/1672 [accessed 26/08/2020].

Correspondence to:

alemmebrat.kiflu@aau.edu.et

alemmebrat.kiflu@yahoo.com 